\title{
Effects of Functionalization, Catenation, and Variation of the Metal- Oxide and Organic Linking Units on the Low Pressure Hydrogen Adsorption Properties of Metal-Organic Frameworks
}

\section{(Supporting Information)}

Jesse L. C. Rowsell and Omar M. Yaghi*

Department of Chemistry, University of Michigan,

930 North University Avenue, Ann Arbor, MI 48109.
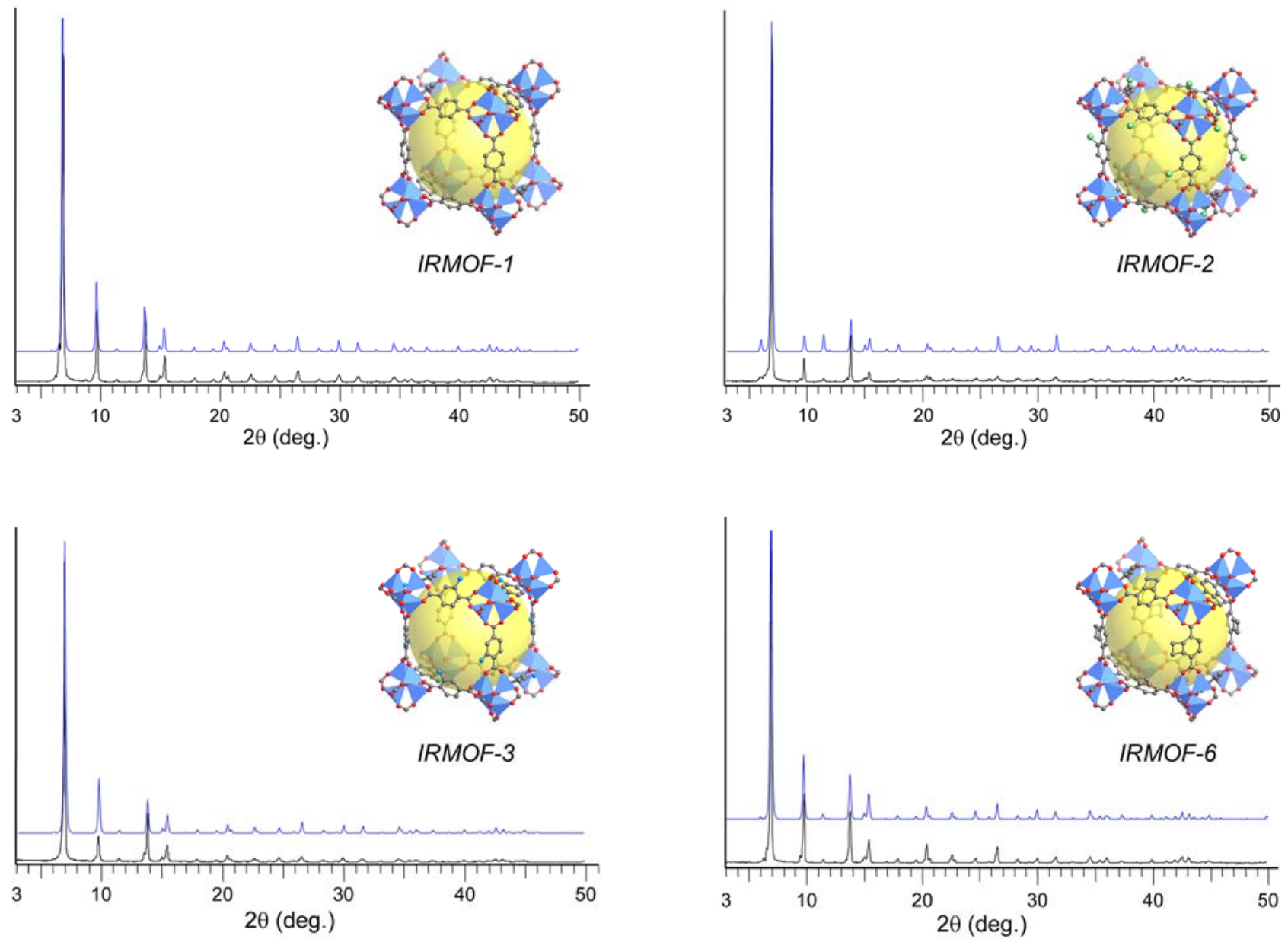

Figure S1. Measured (black) and calculated (blue) powder X-ray diffraction patterns of IRMOF-1, $-2,-3$ and -6 . 

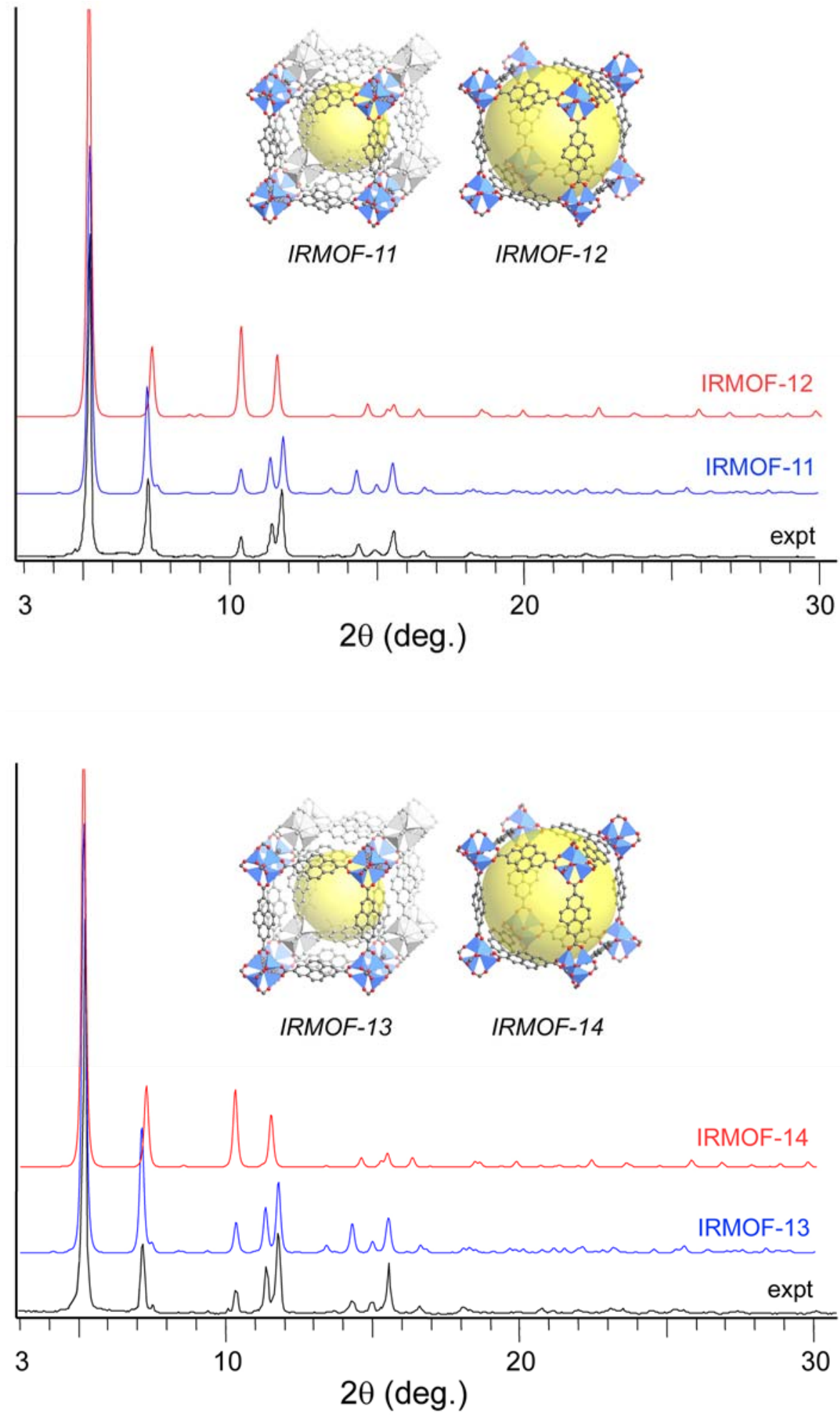

Figure S2. Measured powder X-ray diffraction patterns (black) of IRMOF-11 (top) and IRMOF-13 (bottom) compared to calculated patterns (blue: catenated phase, red: non-catenated phase). 


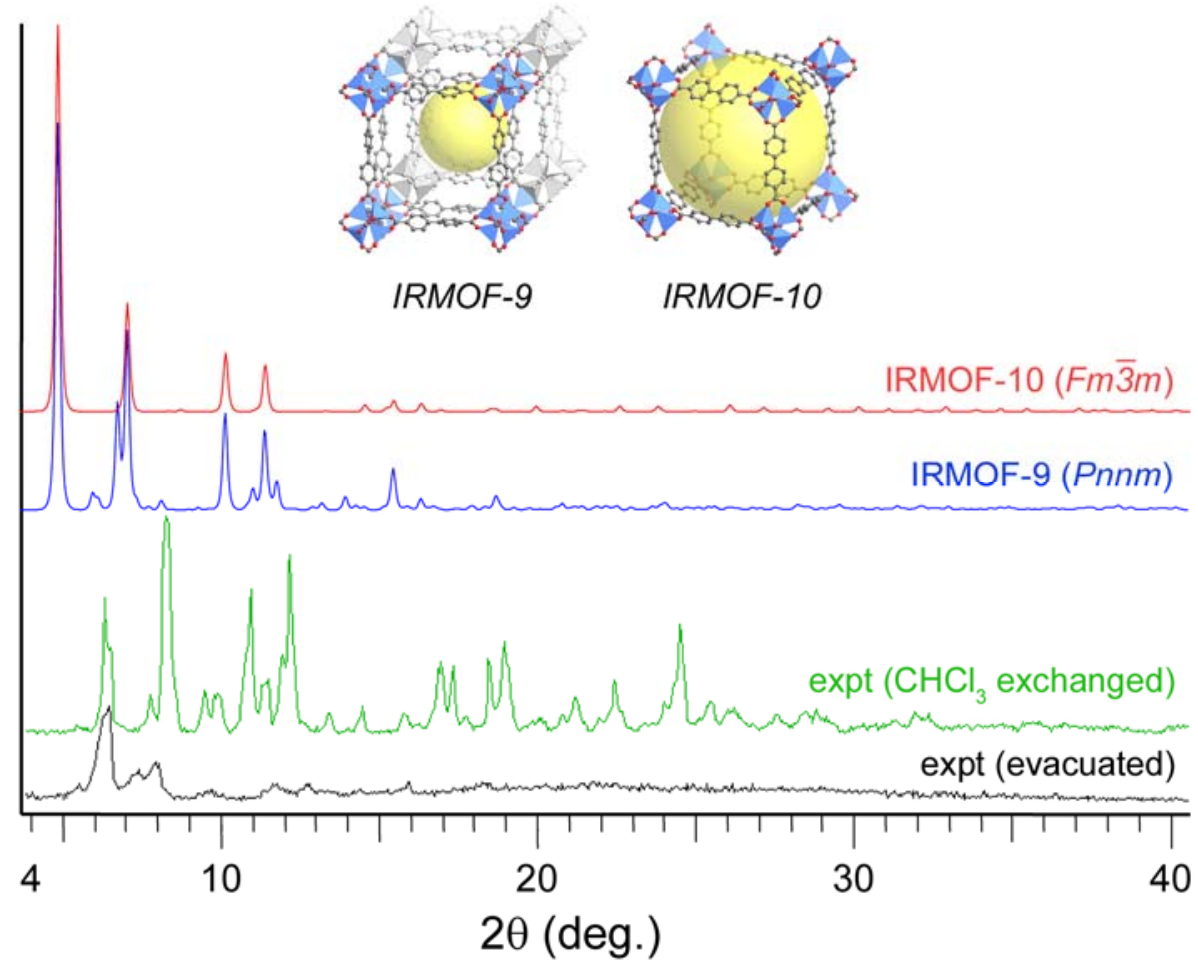

Figure S3. Measured powder X-ray diffraction patterns of IRMOF-9 after $\mathrm{CHCl}_{3}$ exchange (green) and final evacuation (black) compared to calculated patterns (blue: catenated phase, red: non-catenated phase).

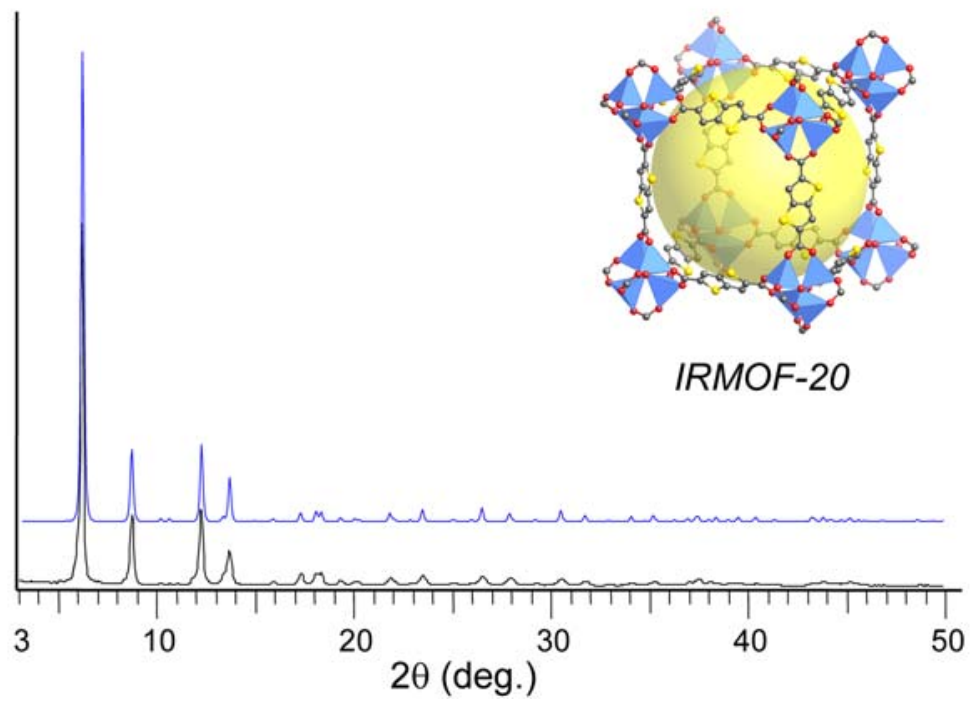

Figure S4. Measured (black) and calculated (blue) powder X-ray diffraction patterns of IRMOF-20. 

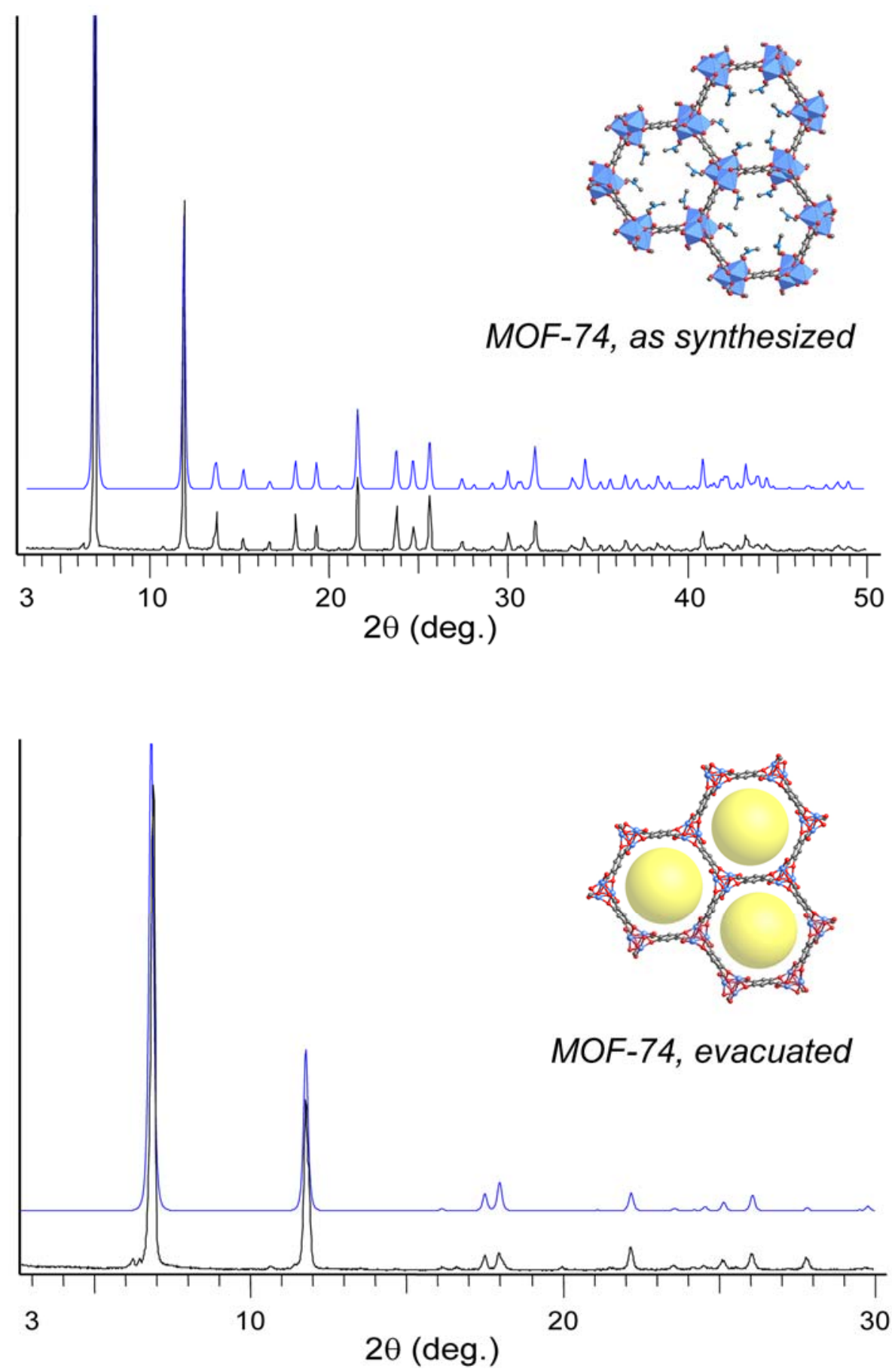

Figure S5. Measured (black) and calculated (blue) powder X-ray diffraction patterns of MOF-74 in the as-synthesized (top) and evacuated (bottom) forms. 


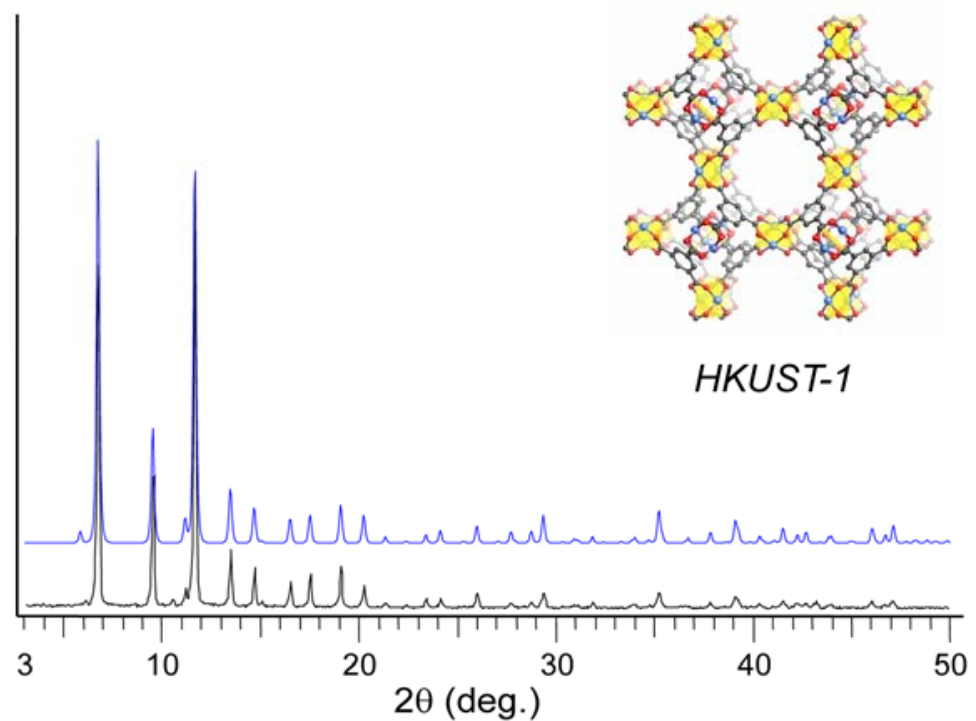

Figure S6. Measured (black) and calculated (blue) powder X-ray diffraction patterns of HKUST-1.

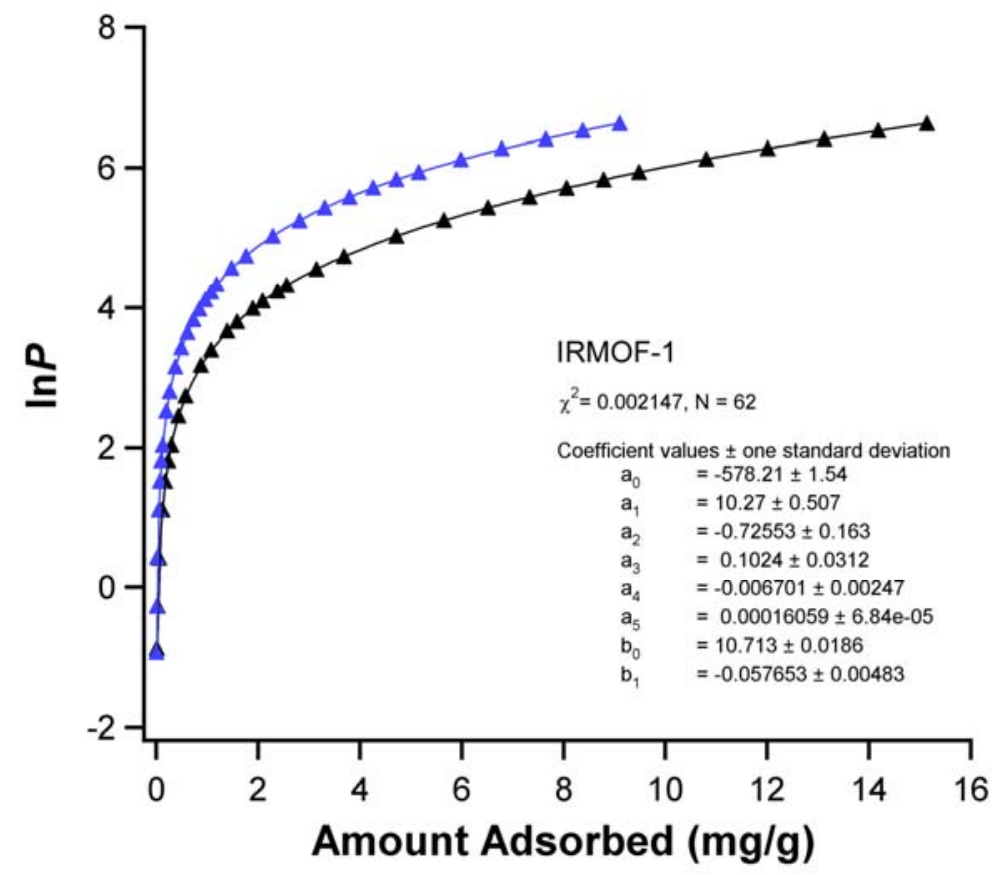

Figure S7. Fitted $\mathrm{H}_{2}$ adsorption isotherms of IRMOF-1 measured at $77 \mathrm{~K}$ (black) and $87 \mathrm{~K}$ (blue). 


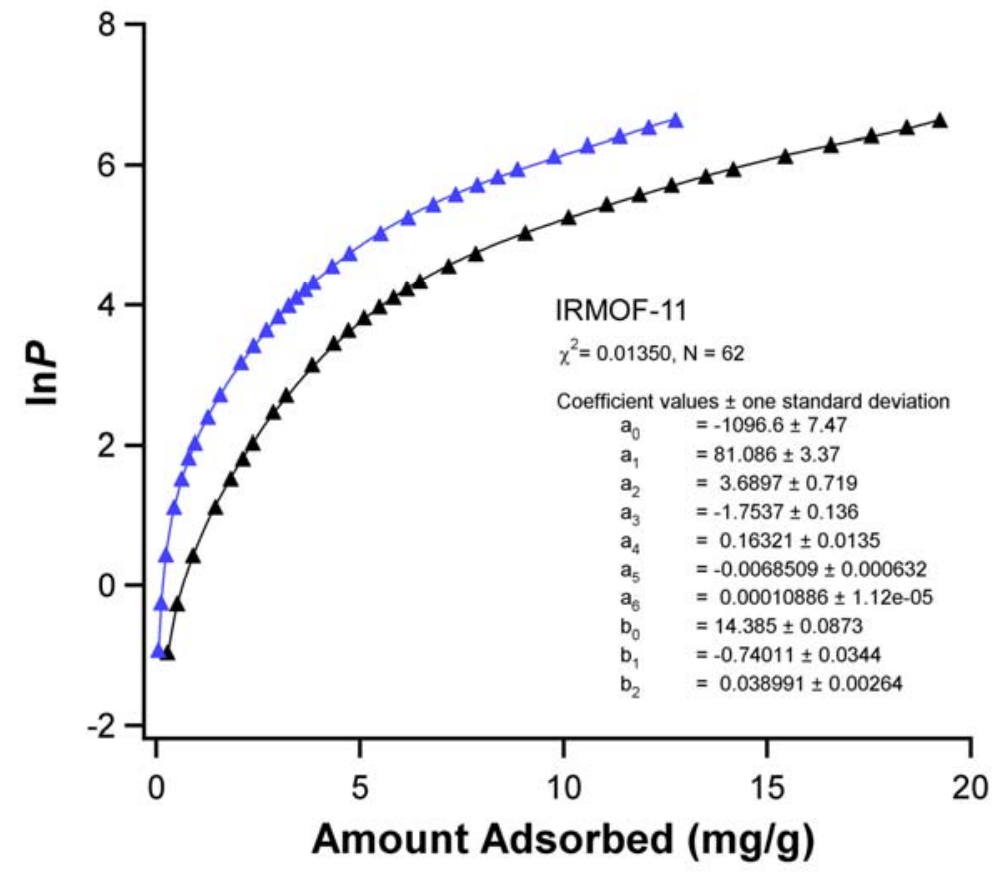

Figure S8. Fitted $\mathrm{H}_{2}$ adsorption isotherms of IRMOF-11 measured at $77 \mathrm{~K}$ (black) and $87 \mathrm{~K}$ (blue).

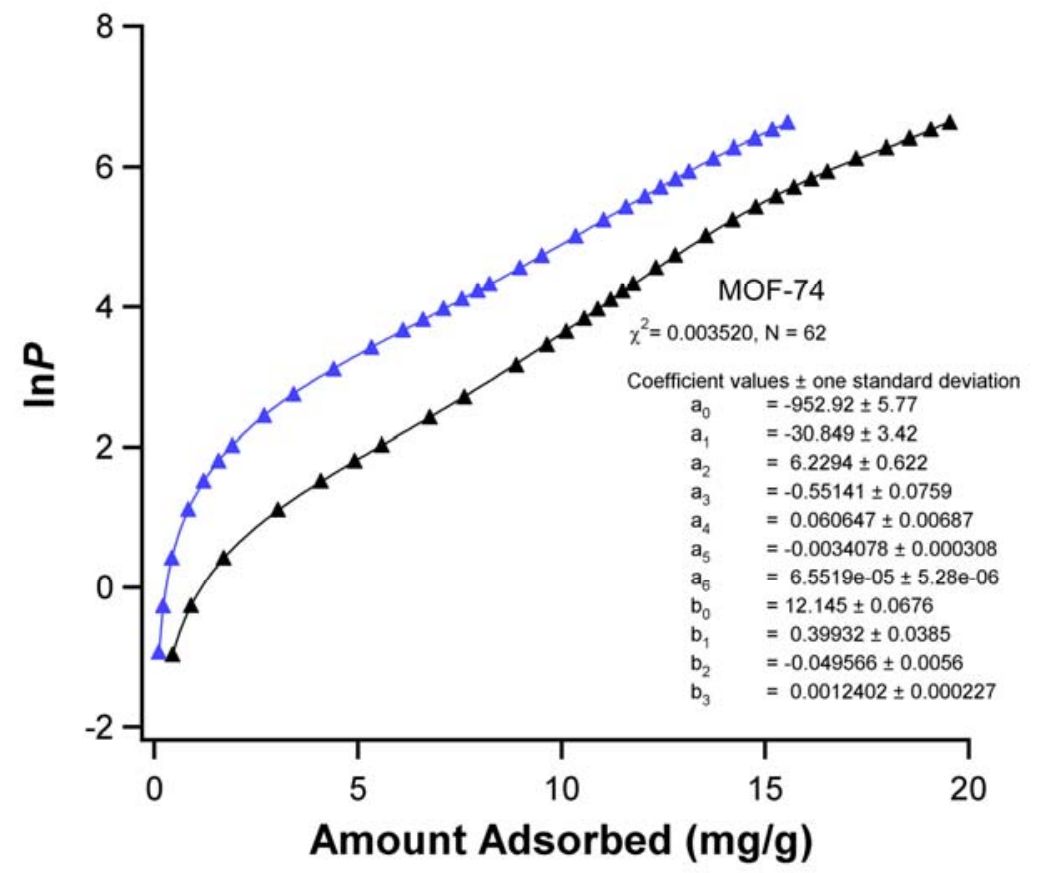

Figure S9. Fitted $\mathrm{H}_{2}$ adsorption isotherms of MOF-74 measured at $77 \mathrm{~K}$ (black) and $87 \mathrm{~K}$ (blue). 


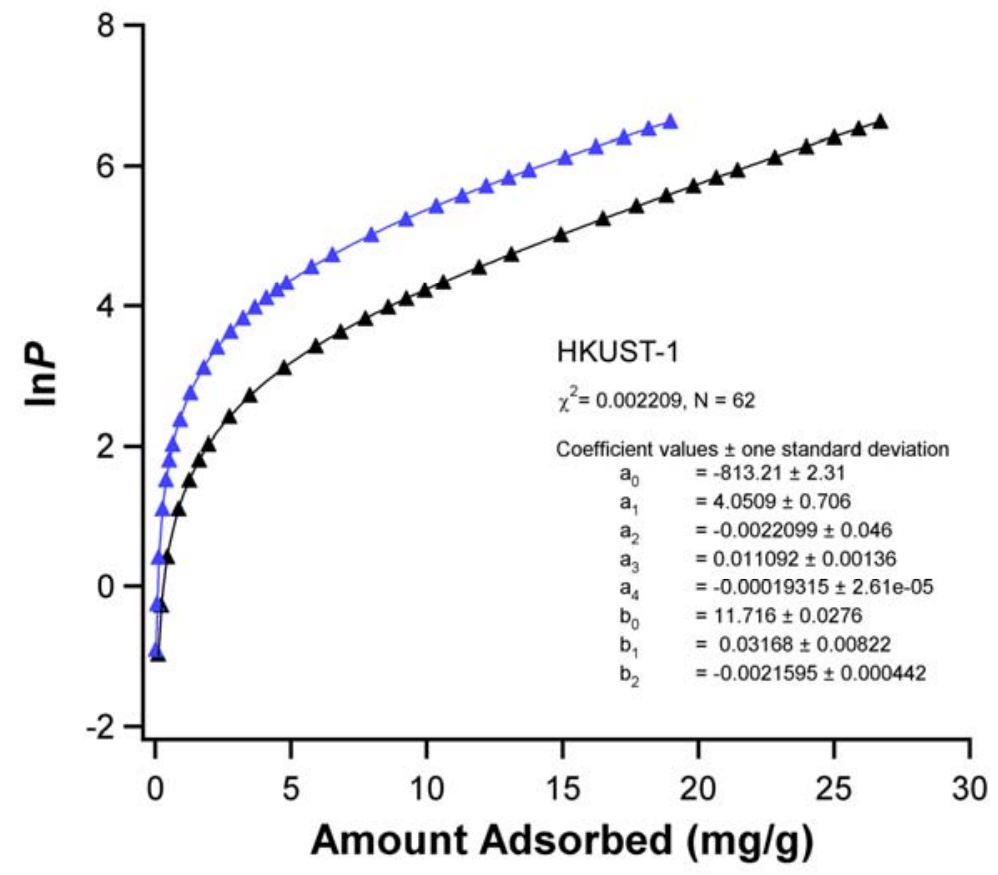

Figure S10. Fitted $\mathrm{H}_{2}$ adsorption isotherms of HKUST-1 measured at $77 \mathrm{~K}$ (black) and $87 \mathrm{~K}$ (blue).

Complete Ref. 2c: Becher, M.; Haluska, M.; Hirscher, M.; Quintel, A.; Skakalova, V.; DettlaffWeglikovska, U.; Chen, X.; Hulman, M.; Choi, Y.; Roth, S.; Meregalli, V.; Parrinello, M.; Ströbel, R.; Jörissen, L.; Kappes, M. M.; Fink, J.; Züttel, A.; Stepanek, I.; Bernier, P. C. R. Physique 2003, 4, 1055. 